\title{
OBITUARIO
}

\section{ULRICH GEORG ESKUCHE (1926-2008)}

El 9 de octubre pasado falleció el Dr. Ulrich Eskuche a los 82 años. Nació en Hannover (Alemania), en 1926. Sufrió en carne propia los horrores de la guerra, que lo transformó en un pacifista a ultranza.

En 1948 ingresa a la Universidad de Münster/Westfalia y en 1951 a la Universidad de Tübingen donde obtuvo el título de Doctor en Ciencias Naturales en 1954, con la tesis sobre comunidades vegetales de praderas en relación con suelo y régimen de agua (Vergleichende Standortuntersuchungen an Wiesen im Donautal bei Herbertingen), siendo su padrino el Prof. Dr. W. Zimmermann.

Siendo aún estudiante, su curiosidad por las plantas lo llevó a participar de trabajos de cartografía vegetal, sobre el régimen de agua y los efectos del viento en cultivos y praderas, en el valle del

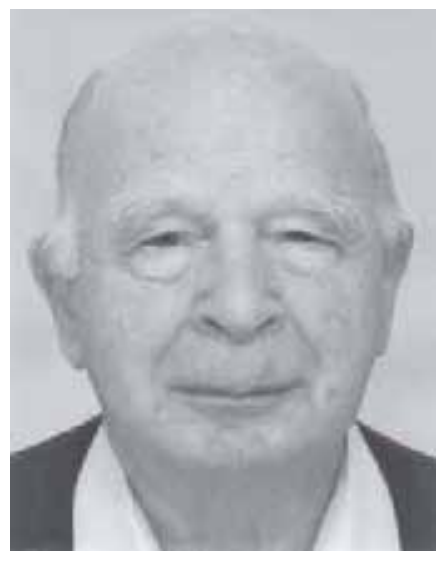
mítico Danubio (1947 a 1953). Trabajó en su tierra natal para varias instituciones, entre ellas el Instituto Federal Alemán de Cartografía de la Vegetación, el Instituto Federal para la Ciencia de la Vegetación y el gobierno estatal de Südwürttemberg-Hohenzollern.

En 1964 comienza su peregrinar en Argentina. Llega a la Facultad de Ciencias Exactas y Naturales de la UBA como Profesor Visitante, donde permanece durante 2 años. En 1966 se traslada al Instituto Miguel Lillo y en 1967 a la ciudad de Santiago del Estero para dar clases en el entonces Instituto de Ingeniería Forestal. El mismo año, en octubre, desembarca en Corrientes, llevando a cuestas su colección particular de plantas; se establece en la Facultad de Ciencias Exactas y Naturales y Agrimensura de la Universidad Nacional del Nordeste, donde por más de 40 años numerosas cohortes de estudiantes siguieron sus clases de Introducción a la Ecología y de Ecología Vegetal, prácticamente hasta el día de su muerte.

Fue un admirador de la escuela fitosociológica de Braun-Blanquet, cuyos métodos aplicó y adaptó a los estudios de la vegetación subtropical y tropical en esta parte del continente.

El estudio de la vegetación, particularmente en su relación con suelo y agua, fue su especialidad. Desde su llegada a Argentina, recorrió la Patagonia, las costas bonaerenses, el Noroeste y el Nordeste. El interés por ampliar sus conocimientos lo llevaron a realizar relevamientos fitosociológicos en Brasil, Paraguay, Chile, México, República Dominicana, Venezuela, Santo Domingo y Tahití.

Los bosques patagónicos, la vegetación de dunas de las costas marinas, los bosques de las provincias de Jujuy y Tucumán, la selva y los bosques de Misiones y de Brasil, las selvas riparias de los ríos Parana y Paraguay y los pajonales mesófilos del norte argentino, así como la vegetación antrópica fueron objeto de su curiosidad.

Su larga trayectoria científica se vió plasmada en 57 publicaciones, la gran mayoría de ellas resultados de sus trabajos en Argentina y países limítrofes.

Sus colecciones de plantas sirvieron de base para la creación del «Herbarium Humboldtianum», al que se dedicó hasta el último día. Contiene unos 30.000 especímenes que documentan la labor taxonómica y fitosociológica de Ulrich y sus colaboradores.

Fue coeditor de la revista «Phytocoenologia, Journal of the International Society for Vegetation Science» (Berlin-Stuttgart), y creador y director de los «Folia Botanica Et Geobotanica Correntesiana», con la edición de 20 números.

Ferviente conservador de la Naturaleza, fomentó en sus alumnos el cuidado del ambiente, 
convencido que la educación y el trabajo eran las únicas vías posibles. Incansable, no era fácil seguir su ritmo en las salidas al campo, donde cada especie de planta tenía para él un cúmulo enorme de información que había que descifrar. Ulrich nos dejó el ejemplo de una vida dedicada a su pasión: la vegetación universal.

Y como dijo un amigo, «tanto quiso a esta tierra adoptiva, que la eligió para su descanco final»...

José Luis Fontana

jlfontana@yahoo.com.ar 